\title{
Performance indicators for roadway bridges
}

\author{
A. Strauss, A. Vidovic, I. Zambon, F. Dengg \\ University of Natural Resources and Life Sciences, Vienna, Austria \\ N. Tanasic \\ University of Belgrade, Faculty of Civil Engineering, Belgrade, Serbia
}

J. C. Matos

University of Minho, ISISE, School of Engineering, Civil Engineering Department, Guimarães, Portugal

\begin{abstract}
The performance indicators should, by its definition, allow capturing the life-cycle degradation processes affecting maintenance plans or the remaining lifetime. The qualitative or quantitative performance indicators are obtained through visual inspections, non-destructive tests or monitoring systems. After their quantification and the comparison with the respective performance goals and thresholds, a Quality Control plan should be accomplished. The COST TU1406 Action aims to uniform the European performance indicators, systemize the knowledge on the Quality Control plans for bridges, establish quality specifications and finally to develop the guideline and recommendations for the assessment of performance indicators. This contribution focuses on the current work of the first Working Group, WG1, where the first step is a collection of the key performance indicators at a European level. First those key performance indicators which capture mechanical and technical properties and its degradation behavior are assessed, while the further consideration reflect on the natural aging, quality of the material, service life design methods, and sustainable, environmental, economic and social based indicators.
\end{abstract}

\section{INTRODUCTION}

Road asset management is a task of great responsibility, since it involves vital assets to the community. An efficient transportation network is essential for the modern society from the economic, societal and environmental point of view. Today, it is a challenge for operators to manage road infrastructures under their responsibility in an efficient way, meeting the present and future needs of the community they serve. For this purpose, the authorities need to produce a Quality Control (QC) plan, which should not only define the goals to be achieved by exploiting the road network, but that should also identify the investment needs and priorities based on a life cycle cost criteria. In addition, a proper condition assessment of these assets must be conducted to support the decision-making process regarding their preservation.

Within the roadway bridge management process, the identification of maintenance needs is more effective when developed in a uniform and repeatable manner. This process can be accomplished by the evaluation of performance indicators, improving the planning of maintenance strategies. Therefore, a discussion at a European networking level, seeking to achieve a standardized approach in this subject, will bring significant benefits. Accordingly, a COST Action recently started in Europe with the aim of standardizing the establishment of QC plans for roadway bridges (European Cooperation in the field of Scientific and Technical Research - COST 2014).

In this context, a first step would be the establishment of specific recommendations for the assessment of roadway bridges, namely, used methods for the quantification of performance indicators. A set of reference time periods for these assessment actions should be also presented. A second step would be the definition of standardized performance goals. Finally, a guideline for the establishment of QC plans in roadway bridges would be developed. In these plans, the importance of advanced deterioration prediction models is emphasized.

Accordingly, the COST Action is divided in the following Working Groups (WG): WG1. Performance indicators; WG2. Performance goals; WG3. Establishment of a QC plan; WG4. Implementation in a Case Study; WG5. Drafting of guideline/recommendations; WG6. Dissemination. In this paper a detail description of WG1 is given, namely, of what was being recently developed since it was the first WG to start its activities. A short description of this WG is initially given with the definition of performance indicators, following with the connection between performance indicators concept and life-cycle philosophy. For the quantification of the 
key performance indicators (KPI) a database has been developed and presented in the paper, with the clarification of the data survey process.

\section{PERFORMANCE INDICATORS}

Life cycle analyses methods are used for the assessment of new and existing bridges, as well as for the evaluation of maintenance strategies. Management systems, capturing different degradation processes, are very often used in relation to such lifecycle analyses methods. Such management systems, developed for a structural condition assessment, are usually based on deterministic performance prediction models which describe the future condition by a functional correlation between structural condition attributes, such as the structural age, and the mechanical, chemical and thermal loading processes.

The practical implementation of such models requires detailed information about its variables, but due to the non-consideration of uncertainties in input variables (scattering values), it does not allow any statement about the quality of the prediction. However, probabilistic performance prediction models, which can be considered as a relevant goal, presume the incorporation of uncertainties in the descriptive variables by probability distribution functions and support conclusions about the quality of the performance prediction.

Deterioration could lead to a decrease of performance to such an extent that a structure could not be able to satisfy the basic serviceability and safety requirements before the design life has expired. In order to prevent the premature failure of a construction, structural codes provide several practical principles and application rules such as the use of protective systems for material exposed in aggressive environment, the construction detailing aimed at avoiding the initiation of degradation, the maintenance actions to be regularly performed, etc.

Each construction, during its life cycle, will face with deterioration depending on several factors such as the environmental condition, the natural aging, the quality of the material, the execution of works and the planned maintenance. Therefore, several design procedures based on the prediction of the deterioration that will likely act on the structure will be developed in the framework of the international research. In addition, performance indicators for the present and future structural conditions on deterministic and probabilistic level will be defined and determined. The management systems are supported in QC plans which in turn are supported by performance indicators. Therefore, it is extremely important to analyze such indicators in terms of used assessment frameworks (e.g. what kind of equipment and software is being used), and in terms of the quantification procedure itself. In this particular work package, the objectives will be the collection and analysis of practical and research based performance indicators:

(a) Technical indicators: the goal in the first step is to explore those performance indicators of bridge structures, in the course of international research cooperation, which capture the mechanical and technical properties and its degradation behavior. These properties are already partly covered by norm specifications but not their complex time variable performance. Moreover, environmental condition, natural aging, and the quality of the material regarding to determined indicators will be investigated and evaluated in their meaningfulness. These considerations, however, also include service life design methods, aimed at estimating the period of time during which a structure or any component is able to achieve the performance requirements defined at the design stage with an adequate degree of reliability. On the basis of the quality of input information (mainly concerning with the available degradation models), as sketched in the above description, it is possible to distinguish among deterministic methods, usually based on building science principles, expert judgment and past experience, which provide a simple estimation of the service life, and probabilistic methods;

(b) Sustainable indicators: in addition to technical performance indicators, which characterize the ultimate capacity as well as serviceability conditions, sustainability indicators, environmental based, will be also formulated. These variables characterize the environmental impact of a structure in the course of its total lifecycle, expressed in terms of total energy consumption, carbon footprint $\left(\mathrm{CO}_{2}\right.$ emission), balance of raw materials, etc. These indicators can be separated into direct and indirect indicators, where the former are related to the construction/maintenance itself and the latter are caused e.g. as a consequence of limited functionality;

(c) Other indicators: other sustainable indicators, economic and social based, may be used to evaluate a bridge performance. These indicators capture, based on the technical performance of a structure, additional aspects that may influence the decision process and typically represent the discounted (accumulated) direct or indirect costs associated with construction and maintenance. Summed up over the full life-time, they represent part of or the full lifecycle costs. They can, in the context of multiobjective optimization, be understood as a weighting scheme to arrive to a single objective function that is to be minimized.

\section{LIFE-CYCLE FRAMEWORK}

In an Austrian national project, a framework for the life-cycle assessment for railway constructions, 
specifically of bridges, has been developed. It is of a paramount importance that key performance indicators KPI, performance goals PG and thresholds PT are defined for an each stage of the bridge's lifetime. The connection between the main objectives of a life cycle assessment procedure and main outcomes of the Action has been verified.

The proposed Life Cycle Framework allows an effective life cycle assessment of engineering structures, especially of roadway and railway bridges. The Framework is divided into following sections:

- Database "Condition survey and assessment data"

- Structural elements subjected to damages or degradation processes

- Deterioration mechanisms

- Intervention methods and models

- Life-cycle cost

- System based analyses

The condition survey and assessment level is constructed according to the recommendations of the Model Code MC2010 (fib, 2013). As defined, conservation activities should restore the current condition of a structure to a satisfactory state, include preventive measures which seek to ensure that future condition of a structure remains within tolerable bounds and aim to improve a current condition in order to meet revised performance requirements. The first condition control activities, already after construction, should include inspection, survey, testing and assessment, at which end a Birth Certificate is issued. The Birth Certificate is a document that contains engineering data defining the condition of the structure. The main elements of the intervention plan here are (a) the deterioration function of the relevant element (b) the timing of the necessary interventions, (c) the life cycle costs for the optimized intervention plan. These elements are also displayed in the Birth Certificate. The intervention information includes: the conservation strategy, the intervention times, the theoretical remaining service life, the graphs of all the relevant degradation processes and the graph of the most influential degradation process.

As a part of a second phase, all bridge elements on which damage or degradation processes are going to be detected are listed (such as abutment, deck, piers, foundations, main girder, ...). These bridge elements can be associated with degradation models from the database or on empirical prediction models based on the inspection results. Also the following should be characterized: the bridge type, the type of construction, materials and the environmental conditions.

The deterioration models, which can be applied to the elements of the bridge structure, are hereafter defined. Following deterioration mechanism should, among others, be considered: carbonation, chloride ingress, reinforcement corrosion, prestressed steel

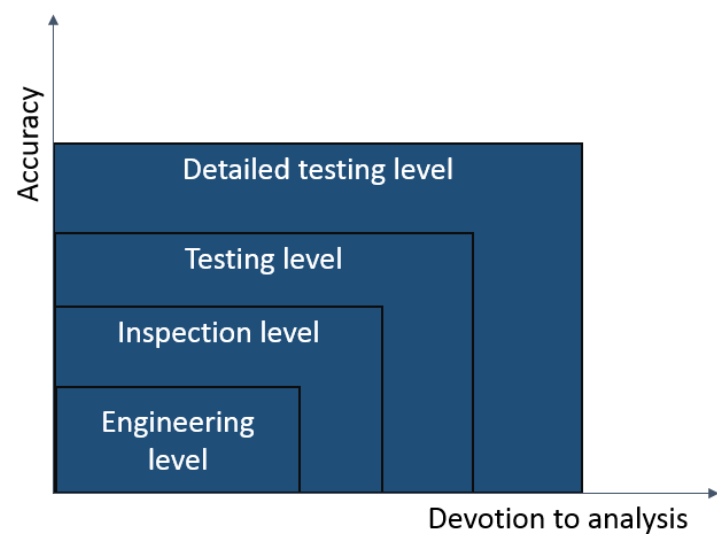

Figure 1. Accuracy of the estimation of a degradation process' behavior

corrosion, freeze-thaw attack, alkali-aggregate reaction, fatigue and mechanical properties.

According to the basic idea of the MC2010 (fib, 2013) and the need for the application of the deterioration models, models can be divided in the levels of approximation (Figure 1):

1. Engineering level - based on the design and implementation documentation

2. Inspection level - based on inspection findings

3. Testing level - based on updating of inspection level by testing results

4. Detailed testing level - based on updating by more detailed testing (laboratory)

Possible intervention strategies are furthermore defined. Interventions have the purpose of repairing, retarding or terminating the damage and degradation processes. MC2010 (fib, 2013) distinguishes between proactive and reactive measures/interventions. Additionally, the distinction has been made between the proposed interventions, where either the protective measure has been applied in order to slow down the deterioration process, or the contaminated parts are removed and replaced with the new ones. There is a possibility also to separate between the strategies which are allowing a reduction in the carrying capacity, and those which are not.

Life-cycle cost, as a total discounted monetary cost of owning, operating, maintain and disposing of a structure, system or infrastructure over a period of time, must be subjected to cost analyses which are essential for evaluation of different repair, maintenance and rehabilitation methods. There could be a necessity that costs are converted to their corresponding present value, since they must be calculated and updated during the whole service life of a structure.

At a final stage of the life-cycle framework, a system model which can represent structural dependencies as well as the interactions between deteriora- 
tions/damages is created. The intention is to make possible to draw conclusions about the cause of damages as well as their relevance and effects on the respective parts of the construction and the structure as a whole (BASt, 2014).

For a consistent characterization of the bridge elements' performance in the Action TU1406 the collection of the performance indicators $P I$, performance thresholds $P T$, performance goals $P G$, and performance methods $P M$ is fulfilled. At the level of deterioration models a collective characterization of performance is again carried out, by applying again $P I, P T, P G$ and $P M$. Furthermore, similar to the bridge elements and the deterioration processes, the collection of performance variables must be provided also for the selected intervention models, as well as for the cost models, and finally on the system and network level. These performance-specific variables are going to be contained in the Action TU1406 database for the evaluation of the bridge elements, deterioration, intervention, cost and system models, where the database uses a standardized coordinatedwording and definitions.

\section{DATA SURVEY}

Through the activities of the WG1 the performance indicators database is currently being enhanced. The core of the survey process for the key performance indicators (KPI) is given in Figure 3. The COST countries must choose beforehand the relevant documents (e.g. inspection, evaluation, research etc.) from which the KPI-s and related information are going to be extracted. To support this process, a user interface is necessary. Here, it must be acknowledged that the amount and level of information varies between documents, even in those of same type. Thus, one of the main requirements in the survey is to allow an unrestricted data input.

The user interface for the survey is structured in MS Excel, where the information may be stored in the four groups: Performance Level, Damage, Performance Indicator/Index and Performance Assessment. Besides this data, there is an opportunity to add additional references and specific information about a group element (e.g. evaluation process, formula, Figure, etc.). The background for this structure comes from screening of the Austrian national document (Bundesministerium für Verkher, Innovation und Technologie, 2011) and two documents from United Kingdom (County Surveyors Society CSS, 2004).

In order to support the interface, the Glossary of key terms is required to store the information and terminology related to PI, PG, PT and PM. It has been prepared on the basis of the information from German and Austrian documents (BASt, 2015, Bundesministerium für Verkher, Innovation und Technologie, 2011). During the screening process it is essential to update the Glossary. Here, every COST TU1406 country should add national specific information in their own language and translate them to English.

Once the survey is finished, the collected data is going to be assessed to clarify the relationships between the key terms PI, PG, PT and PM. This will support the structuring of the Database in Access workspace and further data analysis. The contents of the Glossary and the User Interface are presented in paragraphs to follow.

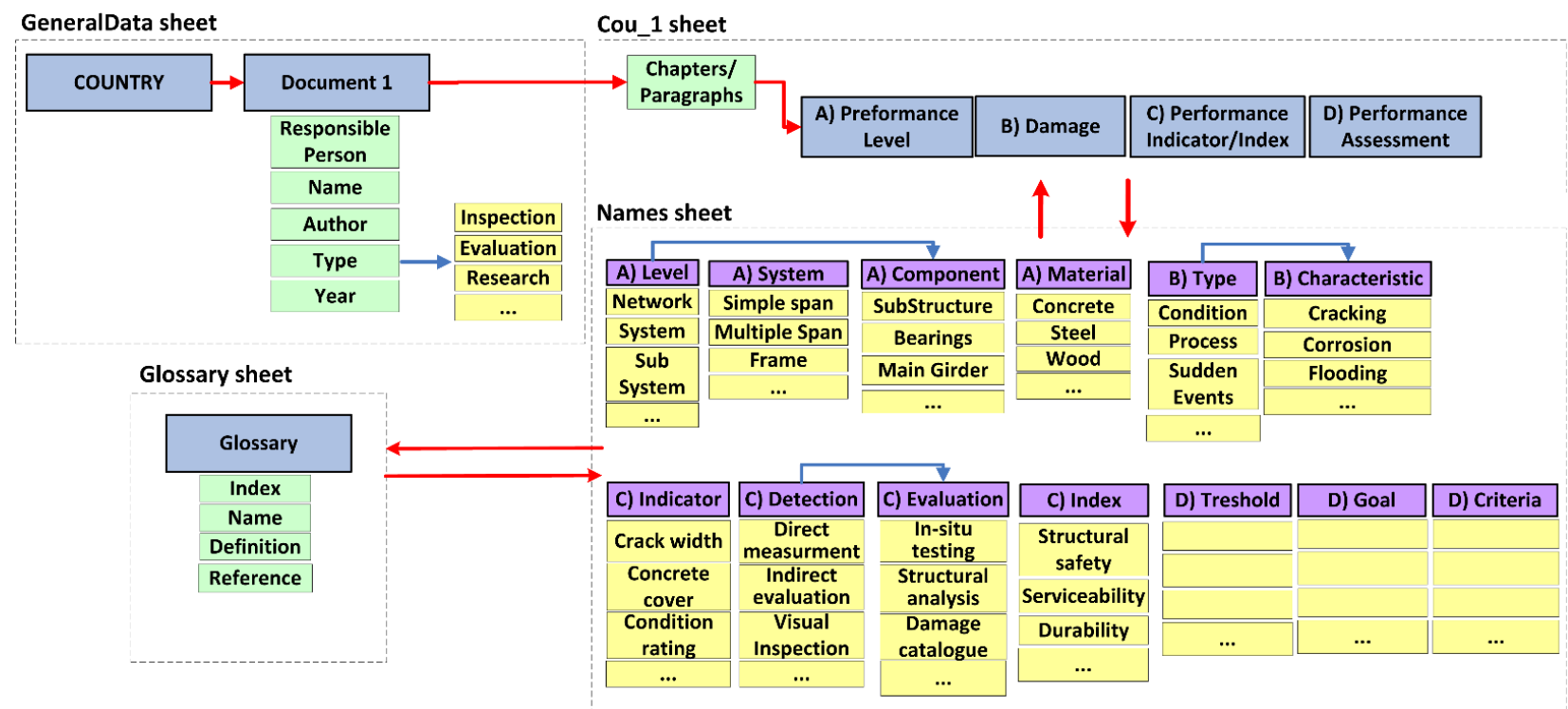

Figure 2. Survey of the national documents for the key performance indicators 


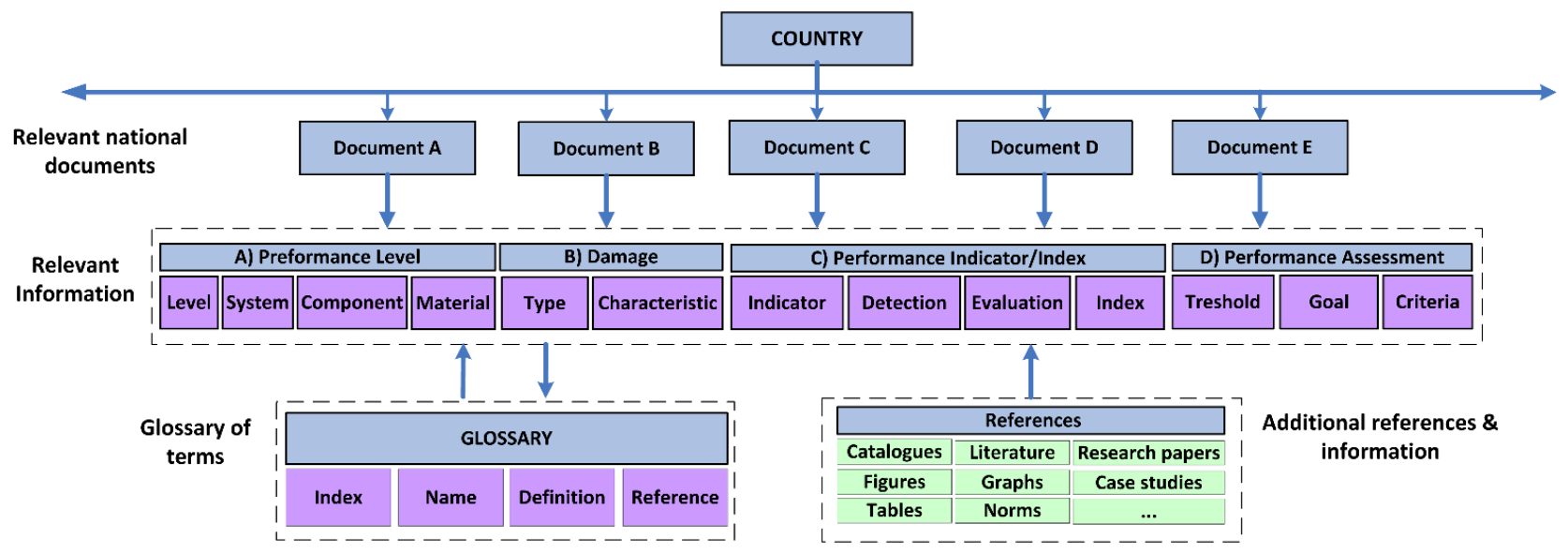

Figure 3: Data structure of the user interface in Excel sheets

\subsection{Glossary}

The Glossary is arranged into the following four parts:

1. Glossary - offers a list of terms with source (reference), definition and keywords. It presents the key concepts, definitions and keywords in relation to PI, PG, PT and PM, which are essential in structuring of the Database.

For instance, deterioration processes are considered to be performance indicators. The damage level can be taken as a performance threshold and robustness as a performance goal. Performance methods are e.g. partial safety factor or (semi)probabilistic concept, stochastic modelling etc.

2. Damages - contains the list of damages affecting roadway bridges (for example, Figure 4. is portraying cracks on the bridge superstructure). Users are invited to fill in the list with additional missing damages in their native language together with the source and translation in English.

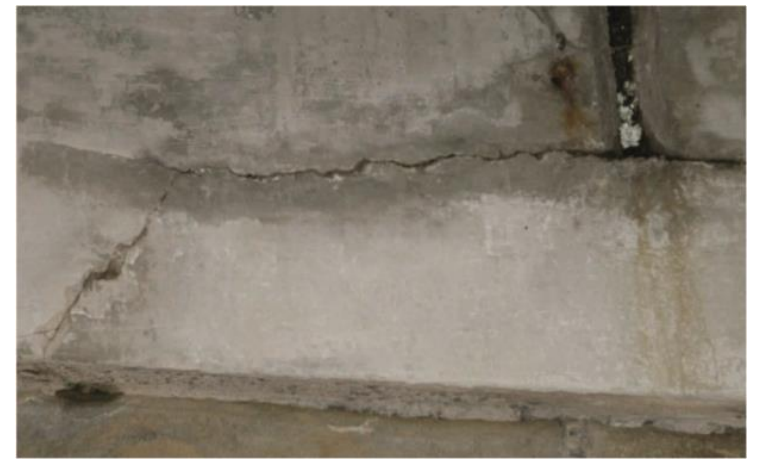

Figure 4: Superstructure cracking (BASt, 2015)

3. New terms - serves for users to add additional concepts, definitions and keywords in relation to PI, PG, PT and PM.
4. Country specific terms - serves for translation of content of the sheet Glossary (terms, definitions, keywords...) to user's native language

\subsubsection{User Interface}

The user interface structure as well as connections between data is given in Figure 3. It is envisioned that every COST participant country receives Excel files with the Glossary and the User interface. The main sheets in the interface are: GeneralData, Cou_Num, and Names_Table sheets.

- GeneralData comprises the basic information on chosen relevant documents for screening.

- Names_Table holds the information of the dropdown lists for Cou_Num sheets and the idea is to append this data simultaneously with the Glossary during the surveying process by users. For instance, by clicking on the category Materials user can choose: aluminium, asphalt, brick, concrete, iron, reinforcement, steel and wood. Drop-down lists are likewise defined for the performance index, performance indicators and levels, bridge elements, damages, detection methods, goals, thresholds etc.

- With regard to the number of documents, there are going to be several Cou_Num sheets. Names of these sheets are automatically given in the form of /first three country letters/_Num, where Num refers to document number in GeneralData sheet. In Cou Num sheets the core information from a specific document is going to be stored. The input of data is realized row-byrow, following the chapters/paragraphs in a document, where the information for each data group is selected from the drop-down lists (Names_Table).

\section{CONCLUSIONS}

In order to compose the KPI Database, the first task is a systematic and comprehensive screening of 
relevant national documents. To support this process, the user interface which allows an unrestricted data input is required. The main goal of the interface, besides the data collection, is to reveal the relationships between the key terms, since they are not defined systematically in the documents. After the comprehensive quantification of the key performance indicators and respective performance goals in the Database is achieved, the establishment of the Quality Control plan will follow.

In the data surveying process 36 countries will be included, which will bring the KPI database on the standardized European level.

\section{ACKNOWLEDGMENTS}

This article is based upon work from COST Action TU1406, Quality specification for roadway bridges, standardization at a European level (BridgeSpec), supported by COST (European Cooperation in Science and Technology). The support of the project "LeCIE - Life-cycle assessment for railway construction - strategies and methods" has been acknowledged.

\section{REFERENCES}

Berichte der Bundesanstalt für Straßenwesen (BASt), 2014, Intelligente Brücke - Konzeption eines modular aufgebauten Brückenmodells und Systemanalyse Schünemann Verlag, Germany (in German)

Berichte der Bundesanstalt für Straßenwesen (BASt), 2015, Intelligente Brücke - Schädigungsrelevante Einwirkungen und Schädigungspotenziale von Brückenbauwerken aus Beton, Schünemann Verlag, Germany (in German)

Biondini, F. \& Frangopol, D.M., 2014, Time-Variant Robustness of Aging Structures, In: Maintenance and Safety of Aging Infrastructure, Structures and Infrastructure Series, Volume 10, CRC Press, Taylor \& Francis Group, 163-200.

Biondini, F., 2012, Discussion of the paper: Time-variant redundancy of ship structures, by Deco, A., Frangopol, D. M., and Okasha, N. M., Society of Naval Architects and Marine Engineers (SNAME) Transactions, 119, 40.

Biondini, F., and Frangopol, D. M., 2010a, Structural robustness and redundancy of deteriorating concrete bridges, Fifth International Conference on Bridge Maintenance, Safety and Management (IABMAS2010), Philadelphia, PA, USA, July 11-15, 2010. In: Bridge maintenance, safety, management and life-cycle optimization, D.M. Frangopol, R. Sause, and C. S. Kusko (eds.), CRC Press, Taylor \& Francis Group.

Biondini, F., and Frangopol, D. M., 2010b, Structural lifetime and elapsed time between first failure and collapse: application to an arch bridge, Fifth International Conference on
Bridge Maintenance, Safety and Management (IABMAS 2010), Philadelphia, PA, USA, July 11-15, 2010. In: Bridge maintenance, safety, management and life-cycle optimization, D. M. Frangopol, R. Sause, and C. S. Kusko (eds.), CRC Press, Taylor \& Francis Group.

Biondini, F., and Restelli, S., 2008, Damage propagation and structural robustness, First International Symposium on Life-Cycle Civil Engineering (IALCCE'08), Varenna, Lake Como, Italy, June 10-14, 2008. In Life-cycle civil engineering, F. Biondini and D. M. Frangopol (eds.), CRC Press, Taylor \& Francis Group, 131-136.

Bundesministerium für Verkher, Innovation und Technologie, 2011, Quality Assurance for Structural Maintenance; Surveillance, Checking and Assessment of Bridges and Tunnels; Road Bridges, Vienna, Austria (in German)

COST Action TU $1406 \mathrm{MoU}$ : European Cooperation in the field of Scientific and Technical Research-COST. 2014. Memorandum of Understanding for COST Action TU1406.

County Surveyors Society CSS, 2004, Addendum to: CSS Guidance Note On Bridge Condition Indicators. Volume 2: Bridge Inspection Reporting, Lincoln, United Kingdom

County Surveyors Society CSS, 2004, Addendum to: CSS Guidance Note On Bridge Condition Indicators. Volume 3: Evaluation of Bridge Condition Indicators, Lincoln, United Kingdom

Ellingwood, B.R., 2005, Risk-informed condition assessment of civil infrastructure: state of practice and research issues, Structure and Infrastructure Engineering, 1(1), 7-18.

fib, 2013. fib Model Code for Concrete Structures 2010. Wilhelm Ernst \& Sohn.

Frangopol, D. M., and Curley, J. P., 1987, Effects of damage and redundancy on structural reliability, ASCE Journal of Structural Engineering, 113(7), 1533-1549.

Strauss, A. (2016) Numerical and monitoring based Markov Chain approaches for the fatigue life prediction of concrete structures Engineering Structures, 112, pp. 265-273.

Strauss, A., Mordini, A., Bergmeister, K. (2006) Nonlinear finite element analysis of reinforced concrete corbels at both deterministic and probabilistic levels Computers and Concrete, 3 (2-3), pp. 123-144.

Strauss, A., Frangopol, D.M., Bergmeister, K. (2010) Assessment of existing structures based on identification Journal of Structural Engineering, 136 (1), pp. 86-97.

Strauss, A., Bergmeister, K., Novák, D., Lehký, D. (2004) Probabilistic response identification and monitoring of concrete structures [Stochastische Parameteridentifikation bei Konstruktionsbeton für die Betonerhaltung] Beton- und Stahlbetonbau, 99 (12), pp. 967-974.

Strauss, A., Wendner, R., Frangopol, D.M., Bergmeister, K. (2012) Influence line-model correction approach for the assessment of engineering structures using novel monitoring techniques Smart Structures and Systems, 9 (1), pp. 1-20.

Strauss, A., Wendner, R., Bergmeister, K., Reiterer, M., Horvatits, J. (2011) Monitoring and influence lines based performance indicators [Modellkorrekturfaktoren als "performance Indikatoren" für die Langzeitbewertung der integralen Marktwasserbrücke S33.24] Beton- und Stahlbetonbau, 106 (4), pp. 231-240. 